\title{
Antisphingolipid antibodies in the sera of leprosy patients
}

\author{
N. VEMURI*, L. M. VIERA*, K. K. TANEJA†, \\ S. V. GANGAL $\dagger \&$ R. MUKHERJEE* $\ddagger$ \\ * Microbiology Division, National Institute of Immunology, Aruna \\ Asaf Ali Marg, New Delhi 110067, India; $\dagger$ Centre for Biochemical \\ Technology, Mall Road, Delhi, India.
}

\section{Accepted for publication 28 November 1995}

\begin{abstract}
Summary Earlier we reported the presence of significant levels of antigalactocerebroside (GalC) antibodies in the sera of leprosy patients. This study corroborates the above result and also gives evidence for the presence of antibodies to the nonpolar ceramide (Cer) moiety of GalC. AntiCer antibody titres were higher as compared to antiGalC antibodies in all categories of leprosy. The specificity of antibodies directed to the Cer moiety was confirmed using Lactosyl-BSA and neutralization assays. Statistically significant and positive correlations were observed between antiGalC and antiCer antibodies. Responsiveness factors were computed using natural logarithmic transformation of the variables.
\end{abstract}

\section{Introduction}

Peripheral nerve damage, leading to anaesthesia and muscular atrophy, is a key feature in the pathology of leprosy. ${ }^{1}$ Mycobacterium leprae, the aetiological agent, selectively infects the Schwann cells of the peripheral nervous system. ${ }^{2,3}$ Nerve damage is seen throughout the spectrum of the disease, but occurs more rapidly and with greater severity in the tuberculoid form (TT) than in lepromatous leprosy (LL). This destruction of the nerve has been attributed to metabolic/biochemical alterations in the Schwann cell $^{4,5}$ resulting from Schwann cell-M. leprae interaction or due to the presence of circulating demyelinating factors. ${ }^{6}$ The occurrence of a vigorous immune response in tuberculoid nerve lesions, which contain very little mycobacterial antigen, suggests that some form of autoimmune recognition may have been induced. The demonstration of high concentrations of autoantibodies to neural protein and lipid antigens in the sera of leprosy patients ${ }^{7-11}$ as well as in $M$. leprae infected Sooty Mangabey Monkeys ${ }^{12}$ is consistent with the speculation that autoimmunity may have a role in neuropathy.

$\ddagger$ Correspondence: R. Mukherjee, Microbiology Division 
Neutral glycosphingolipids (GSL), namely galactocerebrosides (GalC), gangliosides (Gg) and sulphatides (SL) which are abundant in nervous tissues, are known to be immunogenic. AntiGSL antibodies have been well recognized to have a role in some peripheral motor and sensory neuropathies. ${ }^{13}$ Our earlier study gave evidence of circulating antibodies to total nerve lipids and GalC in the sera of leprosy patients, ${ }^{11}$ with antiGalC antibody titres being highest in tuberculoid leprosy patients. However it was observed that there was no correlation between antiGalC antibody titre and the degree or extent of nerve damage in leprosy. ${ }^{11}$ Such an effect suggests that possibly antiGalC antibodies present in leprosy sera lack demyelinating properties. GalC comprises of a galactose residue bound in a $\beta$-glycosidic linkage to a ceramide moiety. Here we report that unlike in other peripheral neuropathies, where the antibodies are directed to the sugar moiety of $\mathrm{GalC}$, in leprosy it is predominantly directed towards the ceramide moiety (Cer). The antiGalC antibodies produced in leprosy may be trapped by $\mathrm{GalC}$ and Cer that are released on degradation of myelin and its constituents.

\section{Materials and methods}

\section{SUBJECTS}

Sera were obtained from a total of 192 leprosy patients attending two leprosy centres in New Delhi: 56 lepromatous leprosy (LL), 36 borderline-lepromatous (BL), 33 borderlineborderline (BB), 33 borderline-tuberculoid (BT), 24 tuberculoid (TT), and 10 neuritic (NEU) leprosy cases. Sera was also collected from 7 patients with other neuropathological disorders (NP), i.e. either Guillain-Barré syndrome, diabetic neuropathy, systemic lupus erythematosus or multiple sclerosis. Normal healthy controls (NOR, 20) were from leprosy nonendemic areas and were of varied socioeconomic groups. The sera were stored at $-20^{\circ} \mathrm{C}$ until use.

\section{ANTIGENS}

Galactocerebroside (Type I and II from bovine brain) was obtained from Sigma Chemical Co., St Louis, Mo. and ceramide was purified from human brain at the Centre for Biochemical Technology, New Delhi. Natural disaccharide-BSA (ND-BSA) and lactosyl-BSA (galactose- $\beta$-(1-4)-glucose-BSA) were provided by Dr Patrick Brennan, Colorado State University, USA.

\section{LIPID ELISA}

Human leprous sera were assayed for the presence of antibodies to GalC and Cer according to our earlier protocol. ${ }^{11}$ The lipids (GalC $4 \mu \mathrm{g} / \mathrm{ml}$; Cer $4 \mu \mathrm{g} / \mathrm{ml}$ ) were suspended in absolute ethanol, coated $(50 \mu \mathrm{l} /$ well $)$ on polyvinyl chloride (PVC) plates and evaporated overnight at room temperature. Nonspecific binding sites were blocked with $3 \%$ bovine serum albumin in phosphate-buffered saline (PBS, $50 \mathrm{~mm} \mathrm{pH} \mathrm{7.4)} \mathrm{at}$ $37^{\circ} \mathrm{C}$ for $1 \mathrm{hr}$. Serum samples were added at a dilution of $1: 100$ as mentioned earlier. Rabbit antihuman IgM horseradish peroxidase conjugate (Dakopatts, Copenhagen, Denmark) was added at a 1:1000 dilution. Substrate consisting of o-phenylene diamine and hydrogen peroxide was added as reported earlier and absorbance was read at $490 \mathrm{~nm}$ using microplate autoreader (EL 309 Biotek Instruments). 
ELISA WITH ND-BSA AND LACTOSYL-BSA

Lactosyl-BSA at $2 \mu \mathrm{g} / \mathrm{ml}$ and ND-BSA at $200 \mathrm{ng} / \mathrm{ml}$ carbonate-bicarbonate buffer $(0 \cdot 2 \mathrm{M}, \mathrm{pH} 9 \cdot 2)$ was coated on PVC plates and incubated overnight at $37^{\circ} \mathrm{C}$. After blocking with 3\% BSA in PBST (PBS containing 0.05\% Tween 20), leprous serum was added at a dilution of $1: 100$ in 1\% PBST. The rest of the protocol was as mentioned above.

\section{NEUTRALIZATION ASSAY}

Fifty microlitre aliquots of $1: 100$ dilutions of a pool of 10 antibody-positive lepromatous (LL) sera were incubated at $37^{\circ} \mathrm{C}$ with varying amounts of lipid antigens (GalC, Cer) suspended in PBS by sonication. After $2 \mathrm{hr}$, the mixture was centrifuged at $10,000 \mathrm{rpm}$ for $3 \mathrm{~min}$ and the supernatant was then added to the ELISA plates coated with known amounts of GalC and Cer as mentioned earlier. The residual antibody present in the neutralized serum was estimated in the plate according to the ELISA protocol.

\section{STATISTICAL ANALYSIS}

Statistical analyses were performed to understand the underlying nature of relationship between variables. Pearsons product moment correlations $(r)$ was calculated for the variables. Regression equations (coefficient $b$ ) were estimated to determine the responsiveness factors.

\section{Results}

The results of individual patients were expressed as the difference between mean absorbance of duplicate wells coated with antigen and the mean absorbance of duplicate wells without antigen $(\triangle \mathrm{OD})$. Sera giving OD readings greater than the second standard deviation (SD) above the mean OD of normal sera were considered to be positive (cut-off point $=$ mean $+2 \mathrm{SD}$ ). Initial screening with sera determined that anticeramide antibody and antiGalc antibodies were primarily of $\operatorname{IgM}$ in nature. Antibodies directed to sulphatide were also measured but detected in only $25 \%$ of the cases and were of very low titres. Hence this antigen was excluded in the subsequent screening (data not shown). The scattergrams in Figures 1 and 2 represents the titres of antiGalC and antiCer antibodies in the sera of leprosy patients. There was a graded reactivity of both GalC and Cer to leprous sera across the spectrum, with a broad range of values. Interestingly, the mean absorbance values of antiCer antibody $(0 \cdot 38-0 \cdot 42)$ were higher than the mean absorbance values of antiGalC antibodies $(0 \cdot 16-0 \cdot 35)$ in all the individual subject groups. However, antiCer antibody titres were higher than that observed in normal and other neuropathies in $82 \% \mathrm{LL}, 75 \% \mathrm{BL}, 60 \% \mathrm{BB}, 81 \% \mathrm{BT}, 66 \%$ TT and $80 \%$ neuritic cases. No correlation was observed between both the antibody levels and extent of lesions, presence or absence of neuritis and deformities. Antibodies to GalC and Cer were absent in normal (NOR) individuals and in patients with other neuropathological disorders (NP).

Two statistical techniques were employed to examine the relationship between 


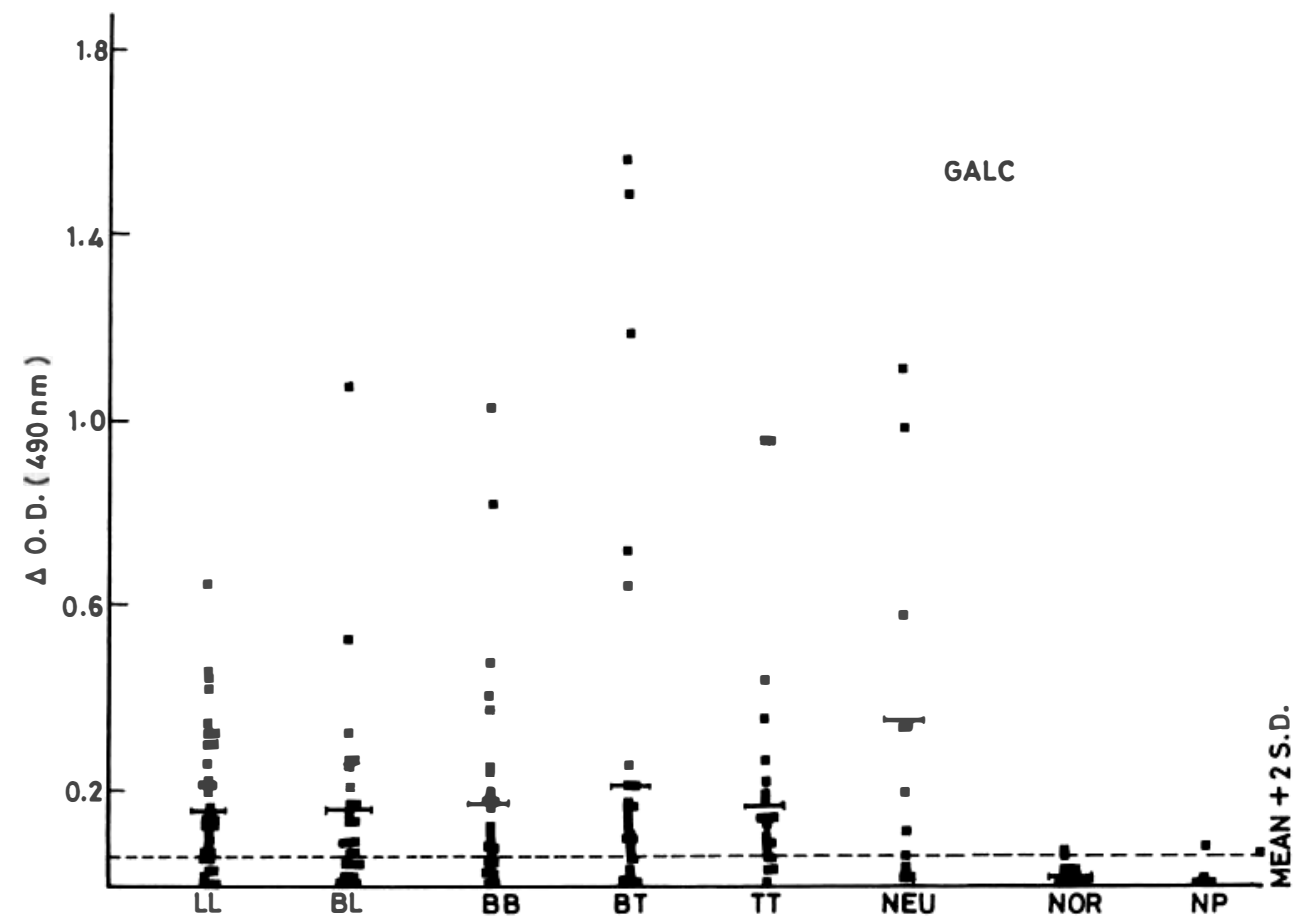

Figure 1. Serum levels of antiGalC antibodies in leprosy patients. Horizontal bar indicates mean value. Mean + $2 \mathrm{SD}=0 \cdot 065$.

antiGalC and antiCer antibodies for different classes of leprosy. Pearson's product moment correlation $(r)$ and regression analysis were performed for these two antibodies (Figure 3). The correlation coefficients for antiGalC and antiCer antibodies show that they are positively correlated and highly significant for all categories of leprosy, as well as for normals. The value of $\dot{r}$ is highest in the case of normals with a value of $0 \cdot 97$. In the case of neuritic (NEU) $r$ is calculated to be $0 \cdot 90$. For BT, TT and BB the correlations are fairly high with values of $0.76,0.75$ and 0.73 , respectively. In contrast the least correlation was found for those classified as BL and LL: $r=0.43$ and 0.44 . But the correlation coefficients do not measure the extent of variation in antiCer that is attributable to antiGalC. For understanding this, a regression analysis using natural logarithmic (ln) transformation of the variables was performed. The results show that normals have the highest regression coefficient (b) with a value of $1 \cdot 11$. The $b$ values of BB and BT are close to $0 \cdot 70$, whereas of BL, LL, BT and Neu are between $0 \cdot 21$ and 0.34 which are all statistically significant.

The reactive group of GalC was delineated by using Cer, ND-BSA and LactosylBSA as individual antigens and tested against sera of leprosy patients. High titre antibodies to ND-BSA was observed throughout the spectrum of the disease (Figure 4). However, the antibody titre to lactosyl-BSA was negligible in all the leprosy patients (Figure 5). This indicates that the antibodies react with the terminal sugar moiety of ND-BSA but do not react with the terminal galactose moiety of lactosyl-BSA. Presence of antibodies to Cer antigen is shown in Figure 2. 


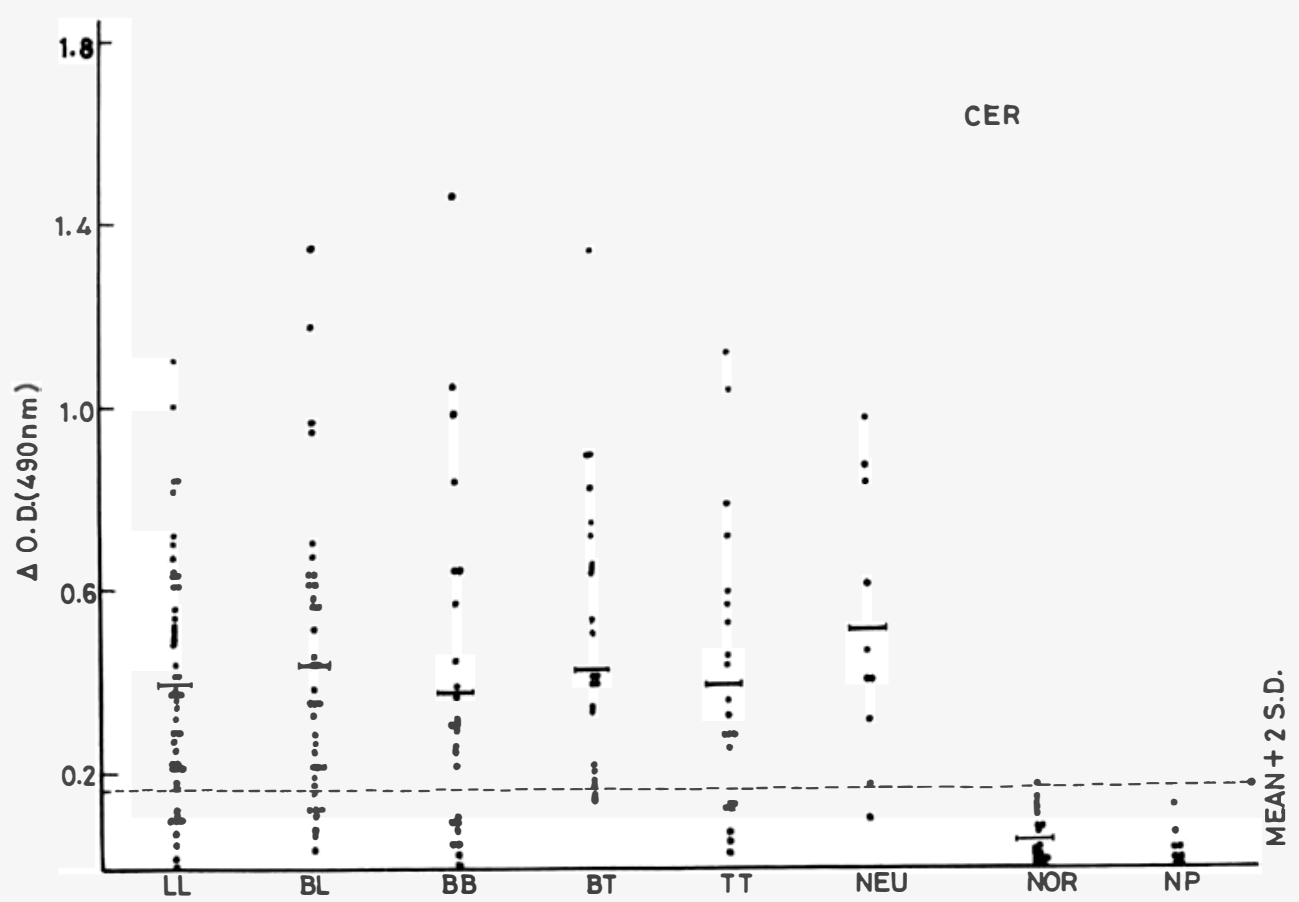

Figure 2. Serum levels of antiCer antibodies in leprosy patients. Horizontal bar indicates mean value. Mean + $2 \mathrm{SD}=0 \cdot 17$.

The cross-reactivity between GalC and Cer was assessed by neutralization assay (Figure 6). Pooled LL sera was adsorbed with varying concentrations of Cer and reactivity was checked against GalC (Figure 6(a)). There was a decline in the level of residual antiGalC antibodies. Similarly, adsorption of LL sera with varying concentrations of GalC and titrated against Cer showed a decline in the level of residual antiCer antibodies (Figure 6(b)).

\section{Discussion}

Circulating demyelinating factors are currently being implicated as mediating leprous neuritis; the precise mechanism by which this occurs remains unknown. Microbial antigens cross-reacting with nerve constituents in a susceptible host has been found to result in an idiosyncratic immune response. The humoral response is at least in part directed to lipid antigens. The importance of lipids in autoimmune responses has been suggested in many studies. Gangliosides, phospholipids and cerebrosides have been shown to potentiate the immune response and contribute to the development of experimental allergic encephalomyelitis. ${ }^{14}$ Antibodies to these glycoconjugates have been implicated to have a role in neuropathies with a possible correlation existing between specific target antigens and clinical symptoms. Of these, antiGalC antibodies have been shown to cause complement dependent demyelination both in vivo and in vitro. ${ }^{15,16}$ 


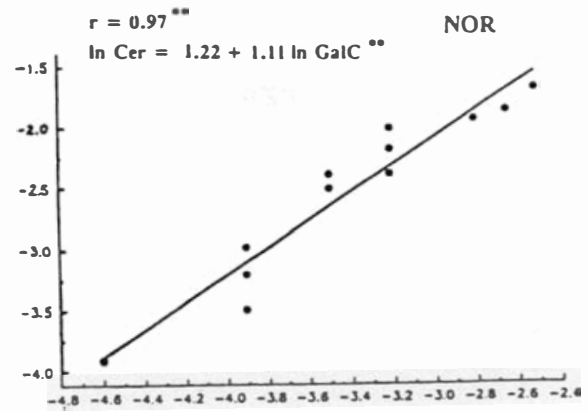

$r=0.46^{\circ}$

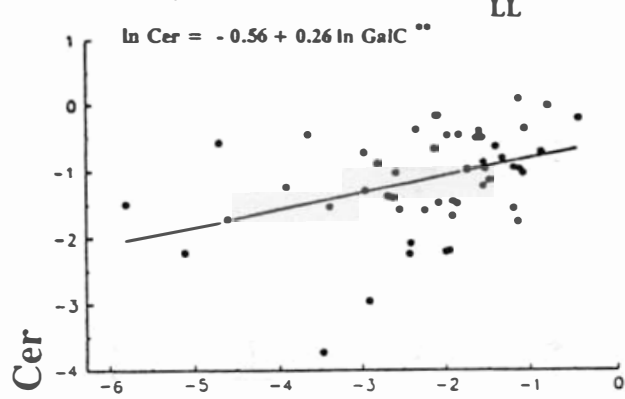

$\underline{E}$

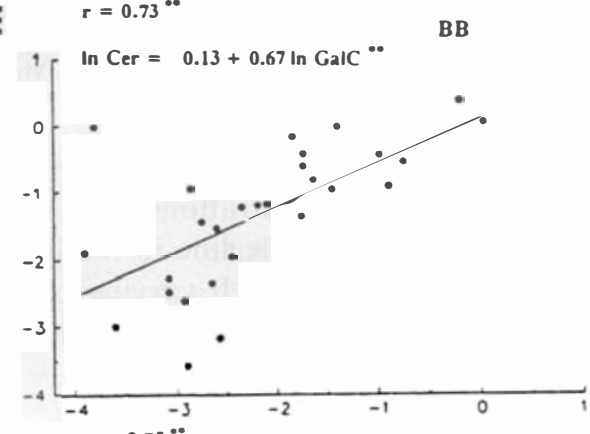

$r=0.75^{\circ}$

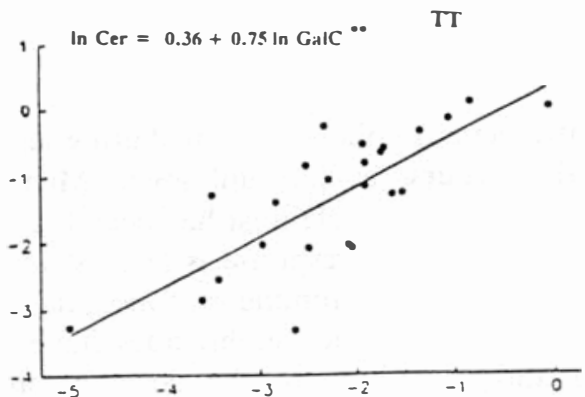

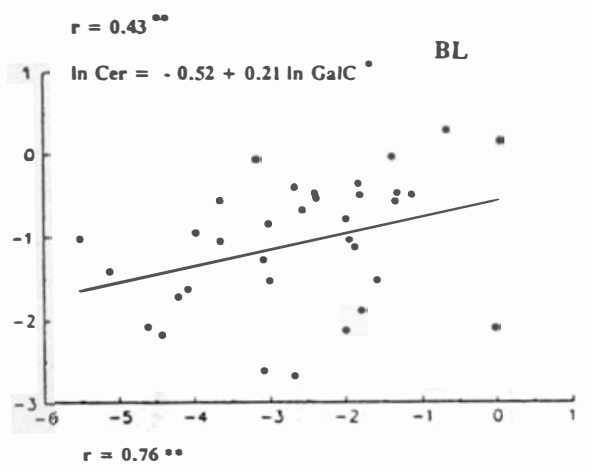
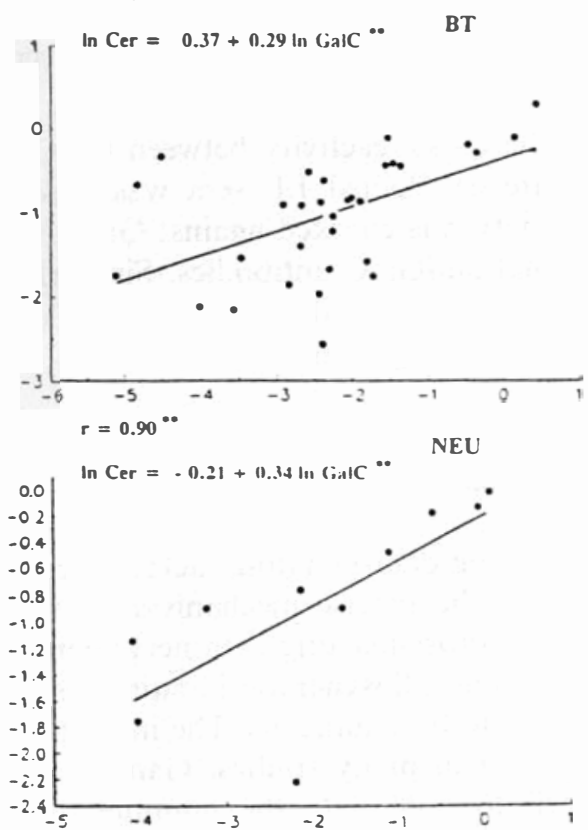

n GalC

Figure 3. Correlation and Regression Analysis between ln antiCer and $\ln$ antiGalC antibodies. In, natural logarithms; *, $p<0 \cdot 05 ; * *, p<0 \cdot 01$. 


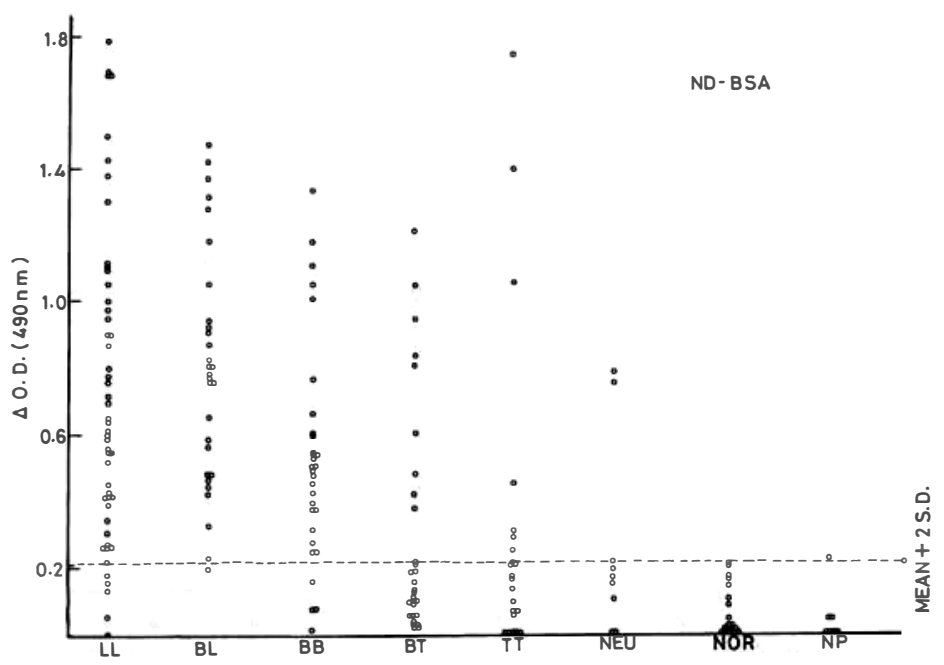

Figure 4. Serum levels of antiND-BSA antibodies in leprosy patients. Mean $+2 \mathrm{SD}=0 \cdot 21$.

Glycosphingolipids are abundant in nervous tissues and accessible to antibodies from the blood. ${ }^{13}$ In the present study, we investigated immunoserologic responses to GSL antigens in leprosy patients and reanalysed their specificities in an attempt to clarify the clinical significance of these antibodies. Antibodies to $\mathrm{GalC}$ and $\mathrm{Cer}$ were found in sera of all categories of leprosy patients. However, antiCer antibody titres were higher as compared to antiGalC titres. On the basis of the above profiles, the reactivities of antiGalC and antiCer antibodies were correlated. A highly significant and positive correlation was observed between the two antibodies in all categories of leprosy patients. As mentioned above, the correlation between the two antibodies decreased towards the lepromatous end of the pole while at the tuberculoid end they were moderately correlated. The above correlation analysis, however does not explain the extent of variation in antiCer that can be associated with variation in antiGalC. This variation is indicated by the regression coefficients $(b)$, the values of which are given above. The regression coefficient values for TT and BB are 1.20 and 1.4, respectively. Changes in Cer that are attributed to GalC are estimated in terms of 'responsiveness factors'. These

LACTOSYL - BSA

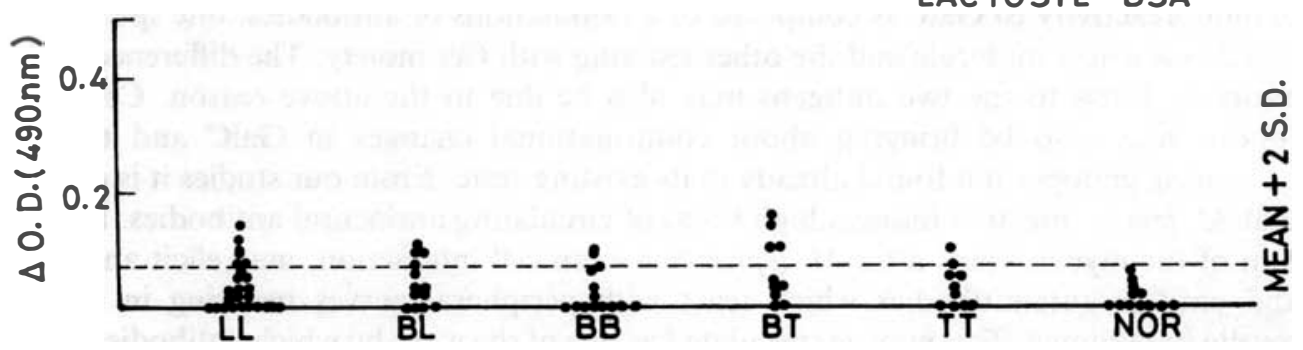

Figure 5. Serum levels of antilactosyl-BSA antibodies in leprosy patients. Mean $+2 \mathrm{SD}=0 \cdot 07$. 
a

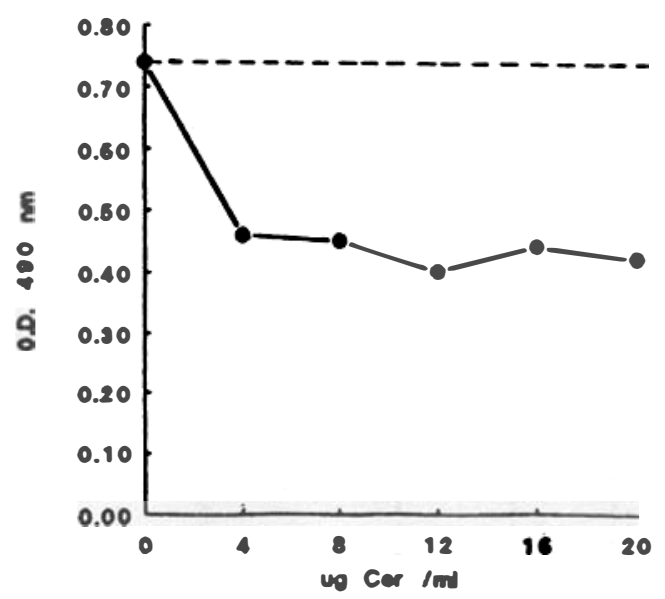

b

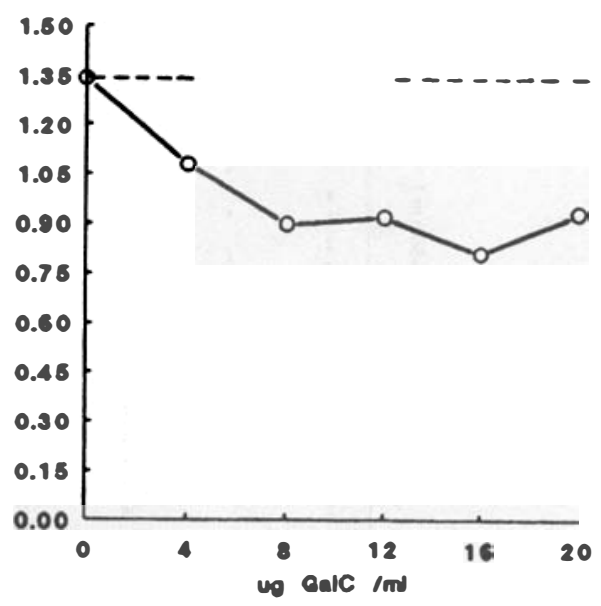

Figure 6. Neutralization assay, (a) Adsorption of LL sera with Cer: reactivity against GalC. (b) Adsorption of LL sera with GalC: reactivity against Cer Dotted line indicates unadsorbed LL sera.

factors, given by the ' $b$ ' values, indicate the percentage change in Cer due to a percentage change in GalC. The responsiveness factors may seem to be anomalous when compared with ' $r$ '. But when the results of the statistical techniques are examined together, it is clear that while LL patients show smaller correlations between Cer and GalC, in the case of TT there is greater responsiveness of GalC on Cer. It is interesting to study such a change in antiCer due to antiGalC since there is evidence that antiGalC antibodies may be involved in oligodendrocyte loss and myelin destruction. ${ }^{17}$ The importance of assessing the role of antiGalC and antiCer antibodies in the nerve damage process in leprosy assumes significance since antiGalC antibodies have been experimentally shown to inhibit the myelination process or cause demyelination in vivo ${ }^{15-20}$ and in vitro. ${ }^{21}$ Ceramide has also been shown to function as an intracellular mediator of apoptosis. ${ }^{22}$ From the neutralization assay studies we can speculate that antiGalC antibodies as well as antiCer antibodies can bind to circulating Cer antigen and thereby inhibit the presence, if any, of Cer induced apoptosis. The absence of antibodies to lactosyl-BSA in leprous sera confirms the specificity of antibodies reacting with the ceramide moiety of GalC. This is one of the first reports whereby antibodies to the nonpolar residue have shown good reactivity and be present in high titres. The possibility also exists that immunoreactivity to GalC is composed of 2 populations of antibodies; one specific for $\mathrm{GalC}$ as a whole molecule and the other reacting with Cer moiety. The difference in the antibody levels to the two antigens may also be due to the above reason. Ceramide residue may also be bringing about confirmational changes in $\mathrm{GalC}$ and thereby presenting epitopes not found already in its existing state. From our studies it is evident that $M$. leprae infection induces high levels of circulating antineural antibodies. Liberation of the myelin lipids after $M$. leprae-Schwann cell interaction, may elicit antiGalC and antiCer autoantibodies which react with peripheral nerves resulting in further myelin breakdown. This may be speculated as one of the ways by which antibodies could cause nerve damage in leprosy. 


\section{Acknowledgments}

This study was supported in part by funds from Council of Scientific and Industrial Research, New Delhi, India. L. M. Viera was a recipient of a WHO fellowship. We gratef ully acknowledge the statistical analysis by Dr P. V. S. Kumar, National Institute for Science Technology and Development Studies, New Delhi.

\section{References}

${ }^{1}$ Bloom BR, Godal T. Selective primary health care: strategies for control of disease in the developing world. V. Leprosy. Rev Infect Dis, 1983; 5: 765-780.

2 Job CR. Mycobacterium leprae in nerve lesions in lepromatous leprosy. Arch Pathol, 1970; 89: $195-207$.

3 Mukherjee R, Antia NH. Host-parasite interelationship between M. leprae and Schwann cells in vitro. Int $J$ Lepr, 1986; 54: 632-638.

4 Mukher jee R, Mahadevan PR, Antia NH. Organised nerve culture. II. DNA synthesis in Schwann cells in the presence of M. leprae. Int J Lepr, 1980; 48: 189-192.

5 Mukherjee R, Mistry Y, Antia NH, Klein N, Vemuri N. Incorporation of ${ }^{14} \mathrm{C}$-acetate into the specific phenolic glycolipid of M. leprae maintained within cultured cells. IRCS Med Sci, 1985; 13: 203-204.

6 Shetty VP, Mistry NF, Antia NH. Serum demyelinating factors and ad juvant-like activity of Mycobacterium leprae: Possible causes of early nerve damage in leprosy. Lepr Rev, 1985; 56: 221-227.

7 Wright DJM, Hirst RA, Waters MFR. Neural autoantibodies in leprosy. Lepr Rev, 1975; 46: 157-169.

${ }^{8}$ Mshana RN, Harboe M, Stoner GL, Hughes RA, Kadlubowski M, Belehu A. Immune responses to bovine neural antigens in leprosy patients. I. Absence of antibodies to an isolated myelin protein. Int J Le pr, 1983; 51: 33-40.

9 Eustis-Turf EP, Benjamins JA, Lefford MJ. Characterization of anti-neural antibodies in the sera of leprosy patients. J Neuroimmunol, 1986; 10: 313-330.

10 Thomas BM, Mukherjee R. Antineural antibodies in sera of leprosy patients. Clin Immunol Immunopathol, 1990; 57: 420-429.

11 Vemuri N, Mukherjee R. Immunoreactivity of nerve lipid antigens in leprosy. J Clin Lab Anal, 1991; 5: $157-161$.

12 Cho SN, Gormus BJ, Xu K, Bohm RP Jr, Walsh GP, Meyers WM, Kim JD. Serologic responses to nerve antigens in Sooty Mangabey monkeys with experimental leprosy. Int J Lepr, 1993; 61: 236-244.

13 Zeballos RS, Fox RI, Cheresh DA, McPherson RA. Antiglycosphingolipid autoantibodies in rheumatologic disorders. J Clin Lab Anal, 1994; 8: 378-384.

14 Hosein ZZ, Gilbert J J, Strejan GH. The role of myelin lipids in experimental allergic encephalomyelitis. Part 2. Influence of disease production by encephalitigenic doses of myelin basic protein. J Neuroimmunol, 1986; 10: $219-233$.

15 Fry JM, Weissbarth S, Lehrer GM, Bornstein MB. Cerebroside antibody inhibits sulfatide synthesis and myelination and demyelinates in cord tissue culture. Science, 1974; 183: 225-248.

16 Raine CS, Johnson AB, Marcus DM, Suzuki A, Bornstein MB. Demyelination in vitro. Absorption studies demonstrate that galactocerebroside is a major target. $N$ Neurol Sci, 1981; 52: 117-131.

17 Webb HE. Antiglycolipid autoimmunity. Possible viral etiology of multiple sclerosis. In: S. Specter, M. Bendinelli and H. Friedman (Eds), Neuropathogenic viruses and immunity, Plenum Press, New York, 1992; 277-302.

18 Hruby S, Alvord EC, Seil FJ. Synthetic galactocerebrosides evoke myelination-inhibiting antibodies. Science, 1977; 195: 173-175.

19 Saida K, Saida T, Brown M, Siberberg D. In vivo demyelination induced by intraneural injection of antigalactocerebroside serum. Am J Pathol, 1979; 95: 99-116.

20 Sergott RC, Brown MJ, Silberberg D, Lisak RP. Antigalactocerebroside serum demyelinates optic nerve in vivo. J Neurol Sci, 1984; 64: 297-303.

21 Roth GA, Roytta M, Yu RK, Raine CS, Bornstein MB. Antisera to different glycolipids induce myelin alterations in mouse spinal cord tissue cultures. Brain Res, 1985; 339: 9-18.

22 Obeid LM, Linardic CM, Karolak LA, Hannun YA. Programmed cell death induced by ceramide. Science, 1993; 259: 1769-1771. 